\title{
El Futuro del Turismo en Venezuela: Cinco Estrategias para reinventar el Turismo
}

\author{
Alfredo Ascanio ${ }^{1}$
}

RESUMEN: Siguiendo los criterios de David Osborne y Peter Plastrik, el trabajo desarrolla el tema de cómo hacer que el Organismo Nacional de Turismo o la Institución Turística Local, sea más eficiente y eficaz, adaptándose al nuevocontexto. Paraello, labase que se seleccionaes latesis que sostiene: que la transformación de la Administración Pública del Turismo sólo puede lograrse cambiando los propósitos (la misión), los incentivos, la responsabilidad a cada nivel de gestión, así como la estructura de poder y la cultura organizacional.

PALABRAS CLAVES: Turismo y administración pública; política turística; estrategias; eficiencia y eficacia.

ABSTRACT: According to David Osborne and Peter Plastrik Criteria, this study shows how the National Tourism Organization or the local tourism institutions can bemoreefficientwith abetterefficacy, adapting theirselvest to the new concept. The public administration improvements depend on the changes in proposals (objectives), incentive plans, abetterdefinition on responsability of each level of administration and the power and the culture of the organization.

KEYWORDS: Tourism and public administration; touristic political strategies; efficacy and efficient.

1. Profesor Titular de la Universidad Simón Bolívar. Economista y Magister en Ciencias Políticas. Postgrado en Gerencia de la Escuela de Graduados de Administración de Negocios de la Universidad de Havard. Candidato al $\mathrm{Ph} . \mathrm{D}$ en Ciencias Políticas.

Dirección: Urb. Alto Prado, calle 10,Qta. Los Helechos, Caracas 1080 - Venezuela. E-mail: aascanio@usb.ve. Su hoja Web es: http://www.freeyellow.com/members4/askain/index.html. 


\section{Introducción}

Osborne y Gaebler (1995) habían escrito un interesante libro titulado La Reinvención del Gobierno. La lectura de esta obra fue casi obligatoria para muchos Alcaldes de Estados Unidos de Norteamérica y para directores de organizaciones burocráticas. Sin embargo, como el libro de Osborne y Gaeble era muy descriptivo y poco prescriptivo, los lectores habían aprobado los criterios que allí se desarrollaron pero no sabían cómo empezar para realizar los cambios. Los autores se decidieron entonces a publicar, en el año de 1997, un segundo libro titulado Banishing bureaucracy - The five strategies reinventing government ${ }^{2}$. Este nuevo título que trataba de cómo alejar o cambiar a la burocracia de un modo de ser no adecuado a un nuevo contex to que busca un Estado más pequeño y productivo y un sector privado más vigoroso, comenzó a ser otra vez una obra que basada en casos prácticos, intentaba explicar el planteamiento complejo de: cómo lograr que la Administración Pública se convirtiera en un organismointeligente, al utilizar mejor sus recursos para aumentar su eficiencia y su eficacia, así como permitir que el sector privado tomara el liderazgo del desarrollo.

Muchos administradores públicos entendieron, al leer el primer libro, que los planteamientos de Osborne y Gaebler, como tesis, sustentaba: cambiar el sistema político, cambiar el sistema parlamentario, poner límites a los mandatos de los gobernantes, diseñar nuevos organigramas, acabar con el despilfarro y la corrupción, reducir la burocracia, hacer una gestión de reingeniería, privatizar más; en fin, ser más eficiente pero de una manera coercitiva. No obstante, aunque algunas de esas acciones se pueden discutir para adaptarias al nuevo contexto, lo que estos autores recomendaban era una tesis mucho más densa que aquellas acciones compulsivas y que muchas veces lo que reflejan es una elevada frustración y poca capacidad de diálogo. De lo que se trataba entonces era de:

- cambiar los fines o propósitos; es decir,revisar la misión según el nuevo contexto;

- cambiar los incentivos para promover el rol que le compete a cada nivel de decisión;

- cambiar las responsabilidades a cada nivel, según sus roles;

- cambiar la manera de repartir el poder dentro de la organización;

- cambiar la cultura organizacional.

Es decir, los autores deseaban organismos públicos que funcionaran y que pudieran presentarresultados "rentables" en la búsquedaconstante de utilizar mejor los recursos de que se disponenen. Los autores estaban pensando en organizaciones

2. Existe traducción al español. David Osborne y Peter Plastrik, La reducción de la burocracia: cinco estrategias

para reinventar el gobierno, Barcélona, Ediciones Paidós, 1998.
3. Rentabilidad no sólo de su gestión institucional, sino rentabilidad social. de un tamaño tal, que se derivase de una estrategia para maximizar el rendimiento, y nosimplemente de reducir o de aumentar personal y recursos como un fi

Las herramientas de gestióneficiente que han desarrollado con insistencia los grandes Gurus de la gerencia privada moderna, como W.E. Deming, P. Drucker y T Peters, no son suficientes para realizar cambios en la Administración Pública. La administración privada y la pública son diferentes por naturaleza. Los organismos públicos - señala Osborne y Plastrik habitan en un océano político y en el seno de sistemas bastantes disfuncioanles (Osborne e Plastrik, 1998:28).

Los fines de los organismos públicos son múltiples y a veces conflictivos, pues tienen que armonizar la eficiencia con la eficacia. Por ejemplo, todos sabemos que un plan integral de turismo se enfrenta con el problema de lograr incentivar a empresas privadas para que sean rentables, pero a la vez el plan necesita cuidar de que se beneficie a la comunidad receptora en su sentido ambiental (natural, cultural y de calidad de vida). Y estos resultados son más difíciles de evaluar y defender, que la rentabilidad privada de un negocio que habita en la economía de mercado, donde cada empresa no tienen muchoque decir o controlar en lomacro, pero si tienen mucho que hacer en cuanto a los cambios micros de sus organizaciones.

Lo primero que aparece entonces es reinventar el sistema administrativo en cuyo seno trabajan los organismos públicos. En el caso venezolano, por ejemplo, cuando los precios del petróleo son elevados se inyecta más dinero al sistema turístico y se comienzan a hacer más cosas, pero no aparecen los verdaderos resultados, porque el sistema per se es disfuncional. En otras administraciones políticas se intentó ser más austeros, lo cual producia recesiones, pero el rendimiento no mejoraba. Otros políticos han creídoque la administración públicaturística se debe manejar como corporaciones privadas, pero las diferencias entre lo público y lo privadoponían restricciones a esos deseos. Otro pensaban que se lograrían mejores resultados con el mito del desarrollismo turístico, sin cambiar las formas de utilizar los recursos, y ello los llevó al fracaso, porque quizá estaban privilegiando "el rescate de minorias y excluyendo las mayorías", para utilizar una frase de Arnaiz y Dachary (1995:363). Si se mejora la gente empleada en la administración pública turística (el burócrata) - se pensaba - la administración puede mejorar; pero resulta que la nueva gente o la gente mejorada, pero atrapada en un sistema obsoleto e ineficiente y poco eficaz, no podría hacer mucho más de lo que podría intentar. Se necesitaba entonces un cambio de paradigma para un nuevo contexto.

\section{EINuevo Contexto}

Todos estamos viviendo en un mundo acelerado donde existe una revolución de las comunicaciones y de la tecnologia.

a aparecerun turista más exigente y profesional del viaje, pero también más consciente del entorno que visita, lo cual lo hace más responsable con el medio. El hecho de que haya aparecido, en los últimos años, el concepto del turismo de naturaleza (llamado ecoturismo), no es más que una huella de que el conceptomismo del turismos de masa, 
agresivo con el medio, ha cambiado y que ahora de lo que se trata es de armonizar turismo y conservación (Ecotourism a guide..., 1996:282).

Incluso, como contraste de lo anterior ya se comienza a mencionar el turismo artificial (hecho porel hombre aplicandotecnologias virtuales), como nuevas formas lúdicas (Cohen, 1996:185). Además, en el momento actual cada país se ha enfrentado a restricciones fiscales y a los monopolios centralizados y jerárquicos de algunas formas de turismo, que son incapaces de innovar y progresar. Incluso existe una opinión generalizada que las Administraciones Públicas del turismo local deberian avanzar privilegiando al inversionista privado y también deberian compensar el buen trabajo de la comunidad anfitriónapromoviendo un desarrollo de servicios integrales queinclusolabeneficie (GiacominiFilho, 1997:44-58). Existe unaespecie de frustración, que es un estado de animo, del ciudadano que habita en muchas comunidades receptoras turísticas, especialmente las más pobres, pero ricas en paisajes y cultura cuando observan que el turismo no los beneficia para que su población pueda prosperar material y espiritualmente.

\section{La Política y la Burocracia}

En América Latina comienza a surgirun nuevo liderazgo político. No obstante, estos nuevos innovadores al comenzar su tarea se sienten incapaces de transformar las burocracias que les toca dirigir. Muchos se dan cuenta que es un problema de comportamiento burocrático; de una cultura que no es fácilmentecambiable durante una administración de gobierno. El instinto de estos nuevos líderes políticos es imponer restricciones drásticas. Controles y más controles. Todo esto no ha logrado producir mejoras continuadas en el sistema. Incluso, las crisis fiscales han inducido a las privatizaciones turísticas, pero muchas de las empresas privatizadas y vendidas a precios muy bajos (debido a la presión de lograr cuanto antes el equilibrio del presupuesto asignado), no han producido el ahorro esperado, pues los ingresos fueron a parar al gasto corriente. También es verdad que muchas privatizaciones de líneas aéreas de bandera, que habían sido monopolios públicos, pasaron a ser luego monopolios privados. Muchas de estas decisiones políticas realmente no han producido cambios de fondo. Utilizando una frase de Osborne y Plastrik (1998:42): "[con esas políticas] no caían otras piezas de dominó".

Algunos programas de mercadeo turístico como no fijaban metas claras para alcanzar en mercados convenientes, ni establecían cuándo se debería realizar, en qué entorno geográfico, a qué costo, y con qué rendimiento, es decir lo que denominamos: planes de gestión con enfoque estratégico y financiero, podían ser acciones solamente "retóricas" y bien "maquilladas". Incluso, se ha comprobado que si estos sistemas y controles no surgen con el entusiasmo de los burócratas, estos no se interesan por los cambios de un sistema, que pueden poner en entredicho su preparacion y sus conocimientos. Incluso es posible que exista un personal en cargos elevados, que hacen casi imposible la buena gestión técnica, porque se interesan más por los asuntos de mantener el poder político, menospreciando las visiones gerenciales de más largo alcance, que son realmente estratégicas. Se desdeña la gerencia, pero se privilegia la política centralizada en unos cuantos; es decir, un uso errado del poder

El problema reside, entonces, en cambiar las instituciones turísticas y su estructura burocrática. Si no existe colaboración y coordinación entre el político, el técnico, el gerente privado y la comunidad receptora organizada (entre la política turística y las instituciones gerenciales para el cambio) es difícil lograr los objetivos establecidos. Para cambiar el sistema, se necesitan acciones estratégicas e integrales que causen un efecto dominó. No se deben proponer estrategias lineales y ordenadas (cartesianas e inflexibles), porque existe un entorno aleatorio con obstáculos que hay que salvar y oportunidades nuevas que hay que saber aprovechar.

En este trabajola definición de estrategiaque hemos adoptado es la misma que utilizaron Osbome y Plastrik, o sea la búsqueda de apoyos múltiples en base a metas bien establecidas:

La utilización de influencias claves y apoyos de los políticos y la sociedad intensas y prolongadas- para llevar a cabo cambios fundamentales quese extiendan por toda la administración pública cambiando todo lodemás (Osborne y Plastrik, 1998:48).

Las estrategias son planteamientos básicos capaces de alterar el equilibrio de fuerzas en el entorno en que se trabaja, al proporcionar cobertura para tácticas operativas concretas. Pero si primero no se averigua cuáles son los mecanismos de influencias políticas que son necesarias persuadir, para distribuir mejor el poder y otorgarle a cada grupo su función principal, incentivando su rendimiento, las estrategias concebidas como un concepto racional no funcionaría como era de esperarse.

\section{Poder Bien Repartido y Rendimiento}

Si no se separa el poder de la alta gerencia del poder de la gerencia operativa, es difícil lograr lo que se desea. Lo primero es separar estos poderes, para que cada uno se ocupe de su función principal; uno, establece las reglas del juego; otro, dirigir el juego hacia metas deseables. El grupo que implementa acciones, tiene que tener un poder bien definido con incentivos para mejorar sus tareas en base a metas de rendimiento. Cuandolos empleados sabenque puedentenerprimas por rendimiento, que mejore sus ingresos, es posible que dejen a un lado el cobro de comisiones "por debajo de la mesa", y otros modos de obtener una remuneración mejor. Los dividendos por eficiencia, para lograr metas, han demostrado que es la mejor manera de hacer que el gasto corriente tenga sentido económico. 


\section{Un Modelo Competitivo Diferente}

La competencia basada en la calidad de los servicios turísticos es otras de las estrategias válidas (Simonetti y Simonetti, 1997). Muchos de estos servicios se pueden subcontratar con empresas privadas o con centros docentes de calidad, sin que sea necesario aumentar la burocracia. Son opciones que pueden ser útiles y que pueden dinamizar la pequeña empresa de servicios local. ¿Porqué la preparación de un plan estratégico de turismotiene que realizarlo la Oficina Municipal de Turismo? ¿Porqué un centro de información para el turistatiene que ser operado por una oficina pública de turismo? ¿Porqué el plan de manejo de un parque o de un centro recreativo tiene que ser operado por la burocracia? La Oficina de Turismolocal, en consulta con el gobierno descentralizado, sólo debería establecer los criterios y definir las políticas, pero estableciendo metas por alcanzar en un tiempo determinado (metas turísticas integrales y ambientales); y en este campo, la Administración Pública debe demostrar su experticia. Los que implementan servicios turísticos, que serían las empresas privadas, deben proporcionar también ideas para el logro de las metas y la comunidad receptora organizada, debe colaborar para lograr el mismo fin. Es decir, hay que negociar; es necesario pactar.

\section{Como hacer que la Comunidad Receptora sea Poderosa}

Como el anfltrión del turista tiene interés en muchas cosas, aparte de sonreír y ser gentil con el visitante temporal, el ciudadano de una comunidad de acogidatiene esperanzas que el turismo, como actividad múltiple, tenga impactos positivos en la calidad de vida donde ese ciudadano reside.

Así como el turista espera que los servicios sean eficientes, así mismo el anfltrión desea que su entornologre las mejoras que el turismo debe proporcionarle, en cuanto a infraestructura urbana, mejores vías de acceso, mejores servicios de educación, vivienda, salud y de seguridad entre otros. Así pues, el turismo no es sólo la promoción de alojamientos para el turista y la planta recreativa para el mismo, sino es un concepto que integra también el desarrollo urbano o rural, para crear un nuevo polode desarrollo. El turismo, entonces es un conjunto de servicios que se transforman en un medio para un fin más noble: el desarrollo comunal.

Como el asunto no sólo consiste en lograr eficiencia turística, sino eficacia comunal, hace falta entonces concebir otra estrategia: las instituciones turísticas tienen que ser directamente responsables no sólo por la calidad del servicio proporcionado al turista, sino por los impactos positivos que deberecibir la comunidad de acogida; y es esta comunidad receptora, la que debe tener el poder suficiente para definir, con sus autoridades, las mejoras que espera al ser seleccionada comoun lugar turístico y las metas para alcanzar esas mejoras.

La comunidad tiene que tener una cuota de poder para decidir. Así como las empresas privadas establecen criterios de calidad para atender a su clientela, la comunidad de acogida tiene que discutir los criterios para beneficiarse del turismo, basándose en las sugerencias de la comunidad organizada.

La calidad de los servicios públicos de esa comunidad deben ser eficientes y amables; y se deben atender las reclamaciones con prontitud para dejar satisfecho al turista; pero la comunidad, como compensación, debe exigir que por cada número deplazasturistas promovida en su localidad, se deben promover un número adecuado de plazas para vivir los trabajadores turísticos, de plazas escolares, de plazas hospitalarias, de servicios ambientales y de seguridad local.

Es decir, el modelo es más complejo porque es más integral, pero es que no tendría sentido desarrollar un buen plan de marketing turístico, adecuado a un buen plan maestro para un sitio turístico, si los que salen más beneficiados son los turistas y las empresas privadas que los sirven, pero continua en el entorno geográfico la misma pobreza y el mismo subdesarrollo.

\section{Los Verdaderos Problemas que se Ocultan tras la Gestión Turistica}

El turismo, que en realidad es un desplazamiento de poblaciones temporales que buscan beneficiarse del entorno de una localidad, tiene que producir más externalidades positivas a ese entorno y colaborar para eliminar los impactos negativos. Si el turismo desplaza a personas con poder de compra a otras localidades, debe existiruna armonía entre recibir y dar. Cada comunidad turística debe definir sus reglas del juego para beneficiarse de esa nueva economia de servicios. El balance neto debeserpositivo. Por ejemplo,cada comunidad que es receptora de turismo, pero que puede llegar a ser también una comunidad emisora de turismo, debe tratar de lograr un mejor equilibrio de su balanza de viajes.

Con el turismo no podemos repetir lo que muchas veces sucedió con el desarrollo industrial y agrícola; o sea, parque industriales o haciendas prósperas, pero en medio de un entorno de pobreza comunal.

Cuando el turista llega a aeropuerto es necesario saber: cómo se le debe tratar, cuáles son las tarifas trasparentes que hay que cobrar por los servicios, cuál es el plazo que se debe establecer para que un turista permanezca el menor tiempo en tramitaciones burocráticas (en los aeropuertos, en las casas de cambio, en los centros de servicios turísticos, en los transportes, en los servicios de correo, etc.). Es decir, la comunidad turística debe elaborar los estatutos para atender al turista; pero también es verdad que el gobierno local, debe establecer el estatuto para beneficiar a la comunidad receptora.Lacomunidad debe darse cuenta que la mejora de su eficiencia, se traduce en una mejora para su comunidad. La comunidad y las empresas privadas debe jugar un rol importante en la organización del turismo, y hacerse responsables de sus actos.

Un buen "posaderó" que tiene un negocio pequeño para atender al turista en el medio rural oun buen hoteleroen el medio urbano, pasa mucho tiempo asegurándose de que sus habitaciones estén a punto, de que la recepción sea eficiente y amable, de que los servicios estén siempre a la hora y sean eficientes. Así, ese gerente espera que con esa actitud su negocio prospere. Las comunidades de acogida deben pensar 
como los "posaderos" y los hoteleros, deben crear las condiciones favorables para que su comunidad sea agradable, limpia, estética y que todo funcione bien, pero esta responsabilidad es del poder político local y de la propia comunidad organizada, que deben compartir el diseño del estatuto comunitario, pero también deben exigir sus compensaciones de calidad de vida.

Todo lo anterior nos lleva a discutir las cinco estrategias para reinventar el turismo del próximo siglos, las cuales son descritas a seguir.

\section{1 - Cuál es el Propósito de ser un Sitio Turístico}

El propósito de ser una comunidad turística es la estrategia central. La comunidad turística tiene que tener una vocación de servicio, pero tiene que establecer su propósito de una manera clara (su filosofia de actuación y su misión). No puede haber contradicciones en sus propósitos turísticos y en su desarrollo. La comunidad debe establecer con claridad hácia dónde quiere dirigirse (qué desea alcanzar como destino único a corto, mediano y largo plazo). En la concepción de este propósito juega un papel clave el gobierno local y la oficina de turismo, la comunidad receptora y el sector privado, porque ellos son los que van a conducir a la comunidad por el camino correcto, en base a las metas y estrategias que hagan del sitio un lugar de calidad total.

Un plan de turismo no sólo consiste en inventariar y poner a punto los "productos turísticos", o establecer metas de crecimiento de los mercados y de las empresas que servirían, sino tiene que establecer también las metas para mejorar el entorno turístico donde reside el anfitrión. Su papel consiste en crear un entorno que anime la inversión privada y la acción comunal, sin aumentar la burocracia. En este trabajo, por ejemplo, se anexa un listado de algunas metas turísticas para los próximos cinco años, con la idea lograr por lo menos casi 2 millones de turistas en el próximo quinquenio, pero la filosoifa turística debe también estar basada en lograr impactos sociales positivos que ese desarrollo puede alcanzar. La misión ya no es sólo establecer políticas para planificar el territorio y alcanzar mercados, consiste también en cómo "sembrar el turismo" con eficiencia (objetivos bien definidos y planes de gestión), para que losefectos sean integrales y produzcan un valoragregado elevado. Para ello se requiere que el director general de una oficina estatal o municipal de turismo sean los responsables de dirigir la oficina, de fijar su rumbo (de timonear), y los empleados operativos sean los responsable de lograr los objetivos al menor costo posible (es decir, la responsabilidad de remar bien).

El que timonea tiene que establecer metas (resultados esperados), por ejemplo: Venezuela debería pasar del puesto n. 12 (en cuanto al índice ponderado de importancia turística) a por lo menos el puesto n. 8 (que es equivalente al índice promedio de Jamaica, Rep. Dominicana, Cuba y Costa Rica) (Ascanio, 1997:85-94), pero para ello debe mejorar su Balanza de Pago Turística, incrementando, en los próximos cinco años, en un millón los turistas extranjeros y mejorar la calidad del producto turístico (mejores normas aereoportuarias y de mantenimiento de equipos), mejorar la facilitación turística y los servicios en general para ser más competitivos promocionando nuevas inversiones turísticas establecidas en forma cuantitativa.

Cada semestre, los que implementan el programa tienen que rendir cuentas a los fines de demostrar las posibilidades de lograr las metas (una guia para negociar las operaciones). Es decir, debe existirun sistema de gestión estratégico, al fijar metas de mediano y largo plazo - un documento sobre el turismo al 2005 y quizá al 2010, en donde se definen las metas de crecimiento y luego convertir las metas en programas prioritarios concretos (áreas de resultados estratégicos y áreas de resultados claves con objetivos)

\section{2 - Cuál es el Mecanismo de los Incentivos que Compensan la Eficiencia}

Los incentivos tanto al turista como a la comunidad receptora son las llamadas estrategias de consecuencias, ya que la gestión por rendimientos es su fundamento. Se basa en un dame para que me des. Te ofrezco eficiencia comunal y te pido calidad de vida local. Es realmente una competencia gestionada por la comunidad que sabe que será beneficiada. Es la concepción de un paquete de gratificaciones que no sólo beneficie al visitante temporal, sino también al anfitrión (a los habitantes, a las empresas turísticas, a la administración turística). Los beneficios que logre la comunidad de acogida van a depender de la calidad de sus servicios turísticos, realizado en un entorno agradable. Igualmente un trabajo innovador de la burocracia para alcanzar los objetivos estratégicos, debe recibir compensaciones adecuadas en adiestramiento y en bonos de rendimiento al comprobarse que se lograron las metas establecidas. Los incentivos al rendimiento deben derivar de los resultados. A su vez el logro de los resultados depende si los que tratan de lograr se someten a una competencia para innovar y mejorar (gestión por rendimientos). Los empleados se motivan si existe:

- éxito;

- reconocimientos;

- desafío;

- interés;

- responsabilidad;

- promoción;

- salarios con prestaciones adecuados al tipo de trabajo.

\section{3 - Cuáles son las Nuevas Responsabilidades que le asegura al Cliente y a sus Anfitriones opciones de Calidad}

La responsabilidad de la alta gerencia turística es establecer los criterios de política general con sus metas bien definidas temporalmente. La responsabilidad de 
la gerencia operativa es lograr esas metas con la mejor utilización de los recursos de que dispone (una gerencia eficiente y eficaz)

La responsabilidad en el sitio turístico es doble. La del servidor turístico y la del turista, pues ambos comparten la responsabilidad de demostrar un comportamiento ejemplar. Esta estrategia no sólo es del cliente, sino de quién lo atiende. Los que prestan el servicio turístico tiene que conocer: cuáles son las metas que se deben alcanzar, cómo deben ser los servicios según esas metas, cuáles son los resultados alcanzados y a quién se le rinde cuenta para obtener un bono de eficiencia. El servidor turístico es responsable de sus actos, los cuales se deben medir por la satisfacción de la clientela turística y del logro de las metas. Pero existe la responsabilidad de político de beneficiar a la comunidad de acogida, cuando dia es eficiente. Así, la responsabilidad es dual y es compensatoria. Las opiniones del turista es tan importante para medir la eficiencia, pero las opiniones de quien lo sirve también es un referente válido.

La libertad de elección para el turista que llega a un sitio geográfico, puede ser una estrategia que lo satisfaga más al colocarlo como un decisor que si se obliga a visitante temporal a seguir los pasos de un "paquete turístico" inflexible. Esta estrategia que Osborne denomina del cliente. En el sitio, los turistas pueden decidir por mayoría cuál es el entorno geográfico que les gustaria conocer con mayor prioridad ${ }^{4}$. Los "paquetes" deben tener la flexibilidad suficiente y contar con planes de contingencia en caso de presentarse el caso práctico de tener que satisfacer un deseo de la clientela que no estaba previsto.

El otro asunto son los inspectores de calidad. En el caso del ecoturismo en Venezuela para "paquetes" diseñados por operadores ingleses, ellíder del grupo está constantemente monitoreando si los turistas se están satisfaciendo con loprogramado (turistas observadores de aves). Los criterios de calidad deben ser operativos (el turista no puede esperar más de " $X$ " tiempo al autobús para la excursión del día, etc.). Si un tour no puede cumplir con lo ofrecido debe compensar al visitante de alguna manera, pues tienen que existiravales de de calidad que le garanticen lo que había comprado. Los llamados ombudsman ayudan a la clientela a resolver sus disputas y a lograr que las reclamaciones sean oídas y aceptadas para mejorar el servicio.

\section{4-Cuál es la Modalidad de Poder que debe existir en el Sistema Turístico}

La estrategia de poderes realmente un tipode estrategia de control que permite capacitar a las instituciones turísticas para ejercer sus tareas. Si las instituciones de

4. Esta experiencia la vivió en autor de este artículo en Marruecos, pues al vistar el Soco o mercado de artesanos, había una mayoría que sugería al guía trasladar al grupo a un determinado lugar, pero quizá el guía que ya había negociado de antemano su porcentaje de comisión tenía diseñado en el "paquete" el lugar que era más rendidor para sus propios intereses $\mathrm{y}$ no para el interés de los visitantes. servicios están capacitadas y la comunidad receptora está capacidad también, y bien concientizada, es posible que se pueda disgregar el poder de actuación en muchos lugares, sin peligro de que se hará mal o fraudulento. De allí que la formación permanente es un elemento clave en el nuevo modelo.

El poder central tiene toda la autoridad para actuar en política general y en metas, pero los poderes operativos deben tener muchas opciones y suficiente flexibilidad para mejorar sus servicios y lograr dichas metas. Si cambia la situación o si cambia la clientela, el poder operativo debe cambiar y adecuarse con rapidez y luego debe rendir cuenta de sus rendimientos. Para ello requiere de cuotas de poder. La comunidad organizada también debe participar y para ello, debe estar legitimada a fin de ayudar en la resolución de sus propios problemas turísticos. Los miembros de la comunidad deben ofertar servicios que mejoren la imagen de su localidad, pero para ello se requiera una estrategia de impulsar a la pequeña y mediana empresa turística.

\section{5 - Cuál es la Nueva Cultura Turística que se espera de un Lugar Placentero}

La cultura turística futura se basará en: los valores, las normas o reglas de juego, los códigos de ética, las actitudes del visitante y del visitado, la esperanza de la comunidad de salir favorecida después de ser un buen anfitrión.

Todo ello forma parte de una nueva cultura turística de iniciativas y de actitudes proactivas. Los hábitos de rendimiento, de trabajo, de limpieza, de orden de estética, solamente se logran en una comunidad que recibe como compensación los beneficios de mejorar su entorno local.

El comportamiento se refuerza si la comunidad, a su vez, está segura que el turismo le refuerza sus servicios comunitarios y que no se trata sólo de beneficiar al turista, sino también a su entorno geográfico. Los compromisos afectivos van a surgir conjuntamente con un plan de futuro compartido con el poder político que asegure los medios para alcanzarlo.

Los programas de capacitación son necesarios para que todos sepan realizar el trabajo que les corresponde. Los equipos de trabajos que aprenden unos de los otros. Los grupos comunales de autogestión. Los programas de sugerencias y los acuerdos laborales para mejorar los rendimientos en base a programas de adiestramiento permanente.

Se requiere de otra cultura burocrática y de una nueva cultura empresarial, todas orientadas al rendimiento y a una práctica de gestión orientada al cliente y a la comunidad de acogida.

\section{La Sinergía de las Estrategias}

Las cinco estrategias deben funcionar en forma conjunta y combinadas. La articulación de estrategias produce una sinergía. Las tácticas dependeran de cada 
situación en especial y de los modos de lograr el apoyo político a los programas turísticos. La forma del gobierno local, asi como el clima político pueden facilitar la tarea para implementar las cinco estrategias o puede que se hagan con un ritmo más lento. Las tácticas también dependen del tipo de organismo y su propia naturaleza. En el futuro, lo que si es necesario es aumentar la capacidad de influencia para lograr las metas a costos más bajos (costos materiales, costos sociales y políticos).

\section{Conclusión}

Existe un principio sagrado en los nuevos criterios para negociar acuerdos o pactos: si los actores van a renunciar a algo, tienen que recibir algo a cambio.

El futuro del turismo y la necesidad de reinventarlo, se logra en parte aplicando por lo menos las cinco estrategias descritas en este trabajo y que se basan en una serie de "pactos". El principal pacto es que los políticos deben aceptar un menor control operativo (lo que se llama a veces "la carpintería"), a cambio de un cierto grado de control sobre las políticas generales, las metas y los resultados; y ceder parte de su poder - el poder operativo - a los decisores públicos y privados y a la comunidad de acogida.

A su vez, la burocracia política aceptaria el pacto de ser más eficientes y de realizar un trabajo más arduo, a cambio de unos visitantes más satisfechos, que es parte de su rendimiento, y de unos bonos de eficiencia que eleven sus ingresos; a su vez, la comunidad receptora y organizada, tiene que comportarse como un buen anfitrión, pero a sabiendas de que recibirán, como compensación, una calidad de vida mejorada para toda su colectividad.

\section{Referencias Bibliográficas}

ARNAIZ y DACHARY. 1995. Turismo, modernización y globalización. Estudios y perspectivas en turismo, v. 4 , n. 4 , p. 363.

SCANIO, Alfredo. 1996. Ecotourism. LINDBERG, Kreg; HAWKINS, Donald (ed.). Ecotourism: a guide for planners \& managers. Vermont: The Ecotourism Society, 1993. Estudios y Perspectivas en Turismo, Buenos COHEN, Erik. 1996 . Estudios yulo, v. 8, n. 2, nov.

CIACOMINI FILHO, Gino 1997. Empresa turistica vismo. Buenos Aires, v. 5, n. 2, p. 185

OSBORNE, David y GAEBLER, T. 1995. La reinvención del gobierno. Barcelona: Paidós.

OSBORNE, David y PLASTRIK, Peter. 1998. La reducción de la burocracia: cinco estrategias para reinventar el gobierno. Barcelona: Paidós

SIMONETTI, Célia R. y SIMONETTI, Paulo R. 1997. Turismo \& qualidade: referenciais teóricos para uma prática. Turismo em Análise, São Paulo, v.8, n.2, nov.

\section{ANEXO}

\section{ESTIMACIONES DEL TURISMO VENEZOLANO}

- Se estima que el gasto privado por concepto de turismo (sin transporte) se mantendrá en $13 \%$ del total del gasto de consumo privado. Al incluir el transporte el porcentaje se eleva al $17 \%$ del total. El consumo turístico público será sólo del $1 \%$ del gasto corriente total del sector público. - La formación bruta de capital (inversiones) en turismo se estima en un 3\% de la inversión total del pais. De la inversión total turística el $25 \%$ es inversión hotelera.

El ingreso por concepto de turismo internacional (receptivo) se estima en un $17 \%$ de los ingresos por concepto de exportaciones no tradicionales (no petroleras). Se estima que las exportaciones no tradicionales en Venezuela representan el 10\% del PIB y el turismo el $2 \%$ del PIB

- El egreso de divisas por turismo emisivo desde Venezuela representa el $18 \%$ de las importaciones que realiza el país.

En Venezuela el turismo aporta al PIB el 13\%, pero puede ser del 7\% debido a que el componente importado del turismo se estima en un $50 \%$.

- El turismo es una riqueza importante en las cuentas nacionales y de elevada productividad por unidad monetaria invertida. En efecto por cada dólar que se invierte en turismo se generan US\$ 24 dólares de riqueza turística, cuando en otros sectores económicos la relación es de 1 a 6 . Por cada dólar invertido en turismo ingresan 3 dólares por turismo internacional, esta misma relación en las otras actividades económicas nos indica que por cada dólar invertido en otras actividades se obtiene un dólar por exportaciones no tradicionales.

El empleo turístico en Venezuela: (1) empleo directo 112.791 personas, (2) empleo indirecto 338.373 personas, (3) empleo total 451.164 personas $(6 \%$ de la población económicamente activa). Del empleo total el $42 \%$ corresponde a la hotelería y el $58 \%$ de otras actividades de servicios que apoyan al alojamiento. El alojamiento turístico empleaba durante 1995 más o menos 47 mil personas (empleo directo) y de estas más o menos 3 mil se empleaban en el turismo rural y ecotunsmo.

- En Venezuela existen 430 posadas turísticas y 146 campamentos turísticos. El 60\% de las posadas están ubicadas en Mérida, Táchira, Distrito Federal y Falcón. El 50\% de los campamentos turísticos se localizan en los Estados Amazonas y Bolívar. El otro 50\% se reparte entre los Estados: Barinas, Cojedes, Guárico, Falcón, Mérida, Miranda, Monagas, Sucre y Delta Amacuro. Este turismo de aventura en campamentos capta el $16 \%$ del turismo internacional que llega a Venezuela.

- El 23\% del turismo internacional corresponde al segmento del ecoturismo o turismo de naturaleza. Entre el $5 \%$ al $10 \%$ del turismo doméstico corresponde la segmento denominado turismo rural.

- Actualmente llegan a Venezuela 800 mil turistas internacionales al ano (el $60 \%$ se aloja en hoteles). Más o menos 587 mil llegan via Aeropuerto de Maiquetía; 200 mil via Aeropuerto Santiago Mariño de la Isla de Margarita y 13 mil turistas por los aeropuertos de Barquisimeto y Maracaibo. Del total el 25\% procede de Estados Unidos de Norteamérica. Otro 25\% procede de Europa (Alemania, Italia, España y Francia). El otro 50\% proviene en forma dispersa de más de una docena de paises. Las estimaciones para el ano 2000 son las siguientes: (I) proyección 
con un modelo lineal en base a 12 observaciones : 770 mil turistas por el Aeropuerto de Maiquetí que seguirá representando el $73 \%$ del total y 243 mil turistas por otros aeropuertos del país, es decir un estimado de un poco más de 1 millón de turistas. (2) proyección con un modelo econométrico en base a 25 observaciones: 801 mil turistas por el Aeropuerto de Maiquetía y 296 mil por otros aeropuertos del país, es decir más o menos 1,1 millón de turistas. En resumen: el comienzo del próximo milenio comenzaremos con 1 millón de turistas. No obstante la meta que deberia establecer el país para comenzar el milenio debe ser una cantidad no menor de 1,6 millón turistas internacionales o bien una cantidad ideal de 2 millones de turistas, pues de esta manera aseguramos una Balanza de Viaje positiva, especialmente con Estados Unidos de Norteamérica e Italia.

- Países competidores con Venezuela: Jamaica, Costa Rica, Cuba, Aruba, Argentina, Chile y Brasil. Así pues Jamaica capta 6 veces más turismo norteamericano que Venezuela, Aruba, Costa Rica y Argentina 3 veces más. Cuba y Jamaica captan 3 veces más turismo de Canadá que Venezuela Brasil, argentina y Cuba captan turismo alemán 3 veces más que Venezuela. En cuanto al turismo italiano argentina, Cuba y Brasil 2,5 veces más que Venezuela. En cuanto al turismo español, Argentina 7 veces más y Cuba 3 veces más. El turismo francés 2 veces más que Venezuela hacia Argentina, Brasil y Cuba. Turismo Inglés: Jamaica 8 veces más, Argentina 5 veces más y Brasi 2 veces más. El turismo brasileño, Aruba 4 veces más; y el turismo argentino, Cuba 4 veces más. En resumen: Cuba, Argentina y Brasil son los competidores más agresivos al captar turismo en los mismos mercados que le interesan a Venezuela.

- El turismo le produce a Venezuela más o menos US\$ 650 millones para 1998 del turismo que arriba por el Aeropuerto de Maiquetía. Se estima que el turismo receptivo puede estar produciendo más o menos US $\$ 800$ millones al arribar por todos los aeropuertos que cuentan con aduana internacional.

- El turismo nacional en Venezuela se estima en 2 a 3 millones de visitantes temporales que se alojan en hotelería. Es decir 3 a 4 veces el turismo internacional, lo cual corresponde al $15 \%$ de la población venezolana.

- Los hoteles generan un volumen de negocios (de ventas) estimado en US\$ 450 millones de dólares y el turismo en general produce un volumen de ventas de US\$1,8 millón, y puede llegara US\$ 3,0 millones si se considera el muitiplicador del gasto.

- Venezuela cuenta con 31 mil habitaciones hoteleras y 8.800 habitaciones extrahoteleras (en 40 resort en tiempo compartido). En este momento se están incorporando más de 1 mil nuevas habitaciones en hoteles de 5 estrellas (de lujo y para el segmento del turismo de negocios).

- El país cuenta con más de 1.900 agencias de viaje y turismo y 93 mayoristas de turismo. Cuenta con más de 1.400 guias de turismo; 600 empresas de transporte terrestre y acuático y 30 empresas dedicadas al transporte aéreo de todo tipo.

- 60 instituciones educativas que ofertan la carrera de turismo y hotelería. El INCE turismo prepara más de 6 mil personas al año en formación básica hotelera y 3 mil en formación básica de turismo. Dos Universidades ofrecen la Licenciatura en Turismo y existen más de 8 maestrías en turismo en por lo menos 4 universidades del país.

- En los próximos cinco años será necesario promover 9 mil habitaciones de hoteles de 3 estrellas, 9 mil habitaciones de hoteles de 2 estrellas y 7 mil habitaciones nuevas de posadas turistas.Es decir 5 mil habitaciones por año ( equivalente a 12 hoteles de 3 estrellas por año, 23 hoteles de 2 estrellas por año y 100 posadas turísticas por año hasta el año 2002). Este tipo de alojamiento para el turismo nacional. Es decir, es necesario invertir por año más de US\$200 millones.

- Para el turismo internacional será necesario promover en los próximos cinco años: 2 mil habitaciones nuevas de hoteles de 4 estrellas y 3 mil habitaciones nuevas de hoteles de 5 estrellas (equivalente a 2 hoteles por año de 4 estrellas y 2 hoteles por año de 5 estrellas hasta el año 2002). Es decir, es necesario invertir por año más de US\$ 200 millones.

- En los próximos cinco años se dará empleo a más de 50 mil personas en la nueva hotelería y el empleo directo e indirecto será mayor de 100 mil personas nuevas, o sea casi 20 mil personas por año.

- Se estima será necesario invertir en promoción turística por lo menos US\$ 4 millones por año en los próximos cinco años.

- Si se aprueba la nueva ley de recreación del sistema de seguridad social es posible que un $50 \%$ de la población obrera venezolana pueda ser un primer mercado para vacaciones programadas.

\section{LISTADO DE HOJAS WEB SOBRE LOS ESFUERZOS DEL TURISMO}

\section{VENEZUELANO}

\begin{tabular}{|c|c|c|}
\hline Lugar & Hoja WEB & Enlaces \\
\hline \multirow[t]{6}{*}{ Venezuela } & www.venezuelavirtual.com & $\begin{array}{l}\text { Médanos de Coro, Morrocoy, } \\
\text { Choroni, Los Roques, } \\
\text { Tacarigua, Mochima, La Restinga, } \\
\text { Playa Medina, Turuépano }\end{array}$ \\
\hline & www.chevere.com & Directorio y buscador (turismo) \\
\hline & www.auyantepui.com & Directorio y buscador (turismo) \\
\hline & buho.eud.com & Directorio y buscador (turismo) \\
\hline & www.viajes-venezuela.com & Revista de viajes por Vzla \\
\hline & www.aventurismo.com & $\begin{array}{l}\text { Paquetes ecoturismo en Vzla } \\
\text { Lista de campamentos y posadas }\end{array}$ \\
\hline Caracas & www.une.edu.ve/caracas & \\
\hline \multirow[t]{5}{*}{ Margarita } & www.margaritaonline.com & \\
\hline & www.enlared.neVcaribewinds & Windsurfing \\
\hline & www.enlared.netcalifomia & \\
\hline & www.sni.netwindsurf & Yaque Beach y Casa de Viento \\
\hline & $\begin{array}{l}\text { conk.com/world/margaweb/ } \\
\text { harley.html }\end{array}$ & $\begin{array}{l}\text { Tour en motocicletas Harley } \\
\text { Davidson (en Margarita) }\end{array}$ \\
\hline \multirow[t]{3}{*}{$\begin{array}{l}\text { Amazonas y } \\
\text { Guayana }\end{array}$} & $\begin{array}{l}\text { www.une.edu.ve:80/ } \\
\text { amazonas/ frameep.html }\end{array}$ & \\
\hline & www.guayanaweb.com & \\
\hline & www.venezuelatuya.com/gransabana & \\
\hline \multirow[t]{2}{*}{ Mérida } & www.cormetur.com & Corporación Merideña de Turismo \\
\hline & www.inerida-travel.cptm.ula.ve & Tours \\
\hline Carabobo & www.todocarabobo.com & Turismo y recreación \\
\hline
\end{tabular}




\begin{tabular}{|c|c|c|}
\hline Falcón & mww.megaidea.com/websites/falcon & \\
\hline \multirow[t]{3}{*}{ Coro } & unw.coroweb.com & Buscador Piranha - Turismo \\
\hline & mww.adicora.com & Windsurfing \\
\hline & uww.une.edu.ve/paraguána & \\
\hline $\begin{array}{l}\text { Costas-Aragua } \\
\text { y Carabobo }\end{array}$ & www.une.edu.ve: $80 /$ costas & Turismo estados centrales \\
\hline Los Roques & $\begin{array}{l}\text { mww.gateven.net } \\
\text { posadamediterraneo }\end{array}$ & Posada Mediterráneo \\
\hline Llanos centrales & mww.branger.com & Hato Piñero-Wildlife \\
\hline $\begin{array}{l}\text { Excursión al } \\
\text { Auyantepui }\end{array}$ & $\begin{array}{l}\text { www.mother.com/ cmitham/ } \\
\text { tepui.html }\end{array}$ & El Autantepui-Gran Sabana \\
\hline $\begin{array}{l}\text { Varios sitios de } \\
\text { Venezuela }\end{array}$ & unw.venezuelatuya.com & $\begin{array}{l}\text { Gran Sabana, Mérida, Caracas, } \\
\text { Margarita, Los Roques,PlayaColorada, } \\
\text { Morrocoy }\end{array}$ \\
\hline \multicolumn{3}{|c|}{ Otras herramienta útiles } \\
\hline $\begin{array}{l}\text { Ciudades } \\
\text { mundiales }\end{array}$ & www.city.net & Buscar Caracas \\
\hline $\begin{array}{l}\text { Excursiones } \\
y \text { aventuras }\end{array}$ & mww.lostwordaventures.com & BuscarVenezuela \\
\hline $\begin{array}{l}\text { Red Platino } \\
\text { (Gubernamental) }\end{array}$ & www.platino.gov.ve & Hoja de Corpoturismo \\
\hline $\begin{array}{l}\text { Para hacer } \\
\text { hojas Web }\end{array}$ & www.geocities.com & Buscar el espacio sobre turismo \\
\hline $\begin{array}{l}\text { Para hacer } \\
\text { hojas Web }\end{array}$ & wuw.tripod.com & Buscar el espacio sobre turismo \\
\hline $\begin{array}{l}\text { Para reser- } \\
\text { vaciones }\end{array}$ & unw.expedia.com & Información turistica \\
\hline $\begin{array}{l}\text { Resumen de } \\
\text { noticias Vzla }\end{array}$ & www.vzla.com/weekly & Información venezolana \\
\hline $\begin{array}{l}\text { Programación } \\
\text { cultural Vzla }\end{array}$ & ven-icis.com/ & Eventos culturales \\
\hline $\begin{array}{l}\text { Traducción en } \\
\text { linea }\end{array}$ & $\begin{array}{l}\text { babelfish.altavista.digital.com/ } \\
\text { cgi-bin/translate }\end{array}$ & $\begin{array}{l}\text { Para traduzir en lineas las páginas } \\
\text { Web }\end{array}$ \\
\hline $\begin{array}{l}\text { Traductor del } \\
\text { viajero }\end{array}$ & www.traviang.com/languages & Palabras para el viajero \\
\hline
\end{tabular}

NOTA: Estas hojas Web se pueden utilizar para realizar un primer viaje de familiarización con algunos de los NOTA: Estas hojas Wursticos venezolanos. Existe una variedad de lugares y de empresas turísticas que todavía no pere en las mejores guias de ecoturismo como son:

- Guía de Elizabeth Kline's-Guide To Camps-Posadas \& Cabins-Venezuela (1996-1997);

- La Guía de Valentina Quintero (1996);

- Guía de Miro Popic-Guia Ecoturística de Venezuela (1997);

- Guía de Ildefonzo Arocha- Venezuela-Guía Turística (1997);

- Guía de Chris Doyie- Cruising Guide (Trinidad -Tobago, Venezuela y Bonaire);

- Guía de John Benus- Manual para Viajeros-Venezuela (1997).

\section{Recebido em 12/10/98}

Paradise

Procesado por Alfredo Ascanio de varias fuentes, especialmente para el

Encuentro en Curacao - Caracas, Venezuela (1998). 